\title{
Enhancing Osteoblast Response and Biointegration in vivo: Grown Zirconium Oxide Nanotube Bundles on Zirconium Surgical Screw
}

\author{
Asmaa Hadi Mohammed ${ }^{`}$, Marwa Abdul Muhsien Hassan \\ Department of Physics, College of Science, Mustansiriyah University, Baghdad, Iraq. \\ Corresponding authors. E-mail: marwamedicalphysics@uomustansiriyah.edu.iq; marwamedicalphysics@gmail.com
}

Received: Sep. 4, 2020; Accepted: Apr. 30, 2021; Published: Jul. 19, 2021

Citation: Asmaa Hadi Mohammed, Marwa Abdul Muhsien Hassan,Enhancing Osteoblast Response and Biointegration in vivo: Grown Zirconium Oxide Nanotube Bundles on Zirconium Surgical Screw. Nano Biomed. Eng., 202 I, I3(3): 213-224.

DOI: 10.5101/nbe.v13i3.p213-224.

\begin{abstract}
In this paper, the surface of zirconium implant was improved by growing zirconium oxide nanotubes using a simple chemical method to increase the surface porosity and thus increase the effectiveness of bone fusion. Histopathological examinations showed the filling of the bone lakes at the implant site with live bone cells and the penetration of Haversian canals into the blood vessels. EDXS profile confirmed the signal characteristic of zirconium and oxygen. EDXS profile is another evidence of pure $\mathrm{ZrO}_{2}$ nanotubes formation. EDXS presents peaks between 0.525 and $2.044 \mathrm{kV}$, which indicate the presence of $\mathrm{ZrO}_{2}$ nanotubes. SEM result showed that homogeneous nanotubes are less in diameter with increasing concentration of glycerine.
\end{abstract}

Keywords: $\mathrm{ZrO}_{2}$ nanotube bundles, Bone regeneration, $\mathrm{Zr}$ surgical screw, Biointegration

\section{Introduction}

Tetra zirconium oxide (or zirconium dioxide), also known as zirconia, is a chemical compound of the formula $\mathrm{ZrO}_{2}$, which is in the form of a white crystalline powder. The oxidation status of zirconium in this compound is ${ }^{+} 4[1,2]$. The cubic crystal form of the compound is known as zircon and is used in the field of gemstones as an inexpensive alternative to diamonds. Zirconium oxide is one of the most researched ceramic materials. Pure zirconium oxide has a monoclinic crystal structure at a room temperature [36]. A shift in the structure to the crystalline tetragonal system and to the cubic system occurs when the temperature is raised. On the other hand, the expansion of the volume resulting from the transition from the cubic system to the tetragonal system and then to the mono-tilt system when cooling leads to a great stress on the crystal, which causes cracking. Several other oxides were added to zirconia in order to stabilise the tetragonal and cubic phases, such as magnesium oxide (MgO) and triple yttrium oxide $\left(\mathrm{Y}_{2} \mathrm{O}_{3}\right)$, calcium oxide (CaO) and triple cerium oxide $\left(\mathrm{Ce}_{2} \mathrm{O}_{3}\right)$, in addition to other oxides [7]. Zirconium oxide does not contain any glass material and is therefore stronger and more resistant to cracking than other ceramics. The use of zirconia in dental medicine was announced in 1990, when the zirconium was used in root pegs and as stent implants [8]. Hence its widespread use in various types of compensations and as implants within the bone [8]. Population around the world suffer from oral diseases, the causes of which are tooth decay or gum disease, as the teeth are of great importance to the health of the body [9-14]. Several different studies have been 
conducted to manufacture materials that are similar to the colour, shape and nature of the teeth, due to the difficulty of renewing the anatomical structure of the teeth. In previous years, studies of dental materials developed greatly to ensure better dental treatment because of their great importance for the mouth, as many materials were used, including implants, and this encouraged researchers to conduct studies of zirconium oxide due to its properties that make it maintain similar bone fusion and may outperform other types of implants, for example, titanium implants [1520]. Zirconium oxide is a white substance with high purity, low toxicity, and good mechanical properties as it is corrosion resistant, excellent toughness and chemically stable. Zirconium oxide is used to increase the bone fusion process between the zirconium implant and bone, in this research the surface of the zirconium implant was improved and converted into nanotubes of zirconium oxide, which makes the porosity very high and thus high bone fusion, where it is believed that surface treatment speeds up the formation of new bone [21-28].

\section{Experimental}

\section{Synthesis zirconium oxide nanotube bundles}

Zirconium Oxide Nanotube Bundles are prepared by using electrochemical method. Zirconium surgical screw used in this work as shown in Fig. 1 (99.999\% purity, $\mathrm{A}=$ smooth part, length: $3 \mathrm{~mm}, \mathrm{~B}=$ threaded part, length: $5 \mathrm{~mm}, \mathrm{C}=$ length of slit: $1.5 \mathrm{~mm}, \mathrm{D}=$ diameter of slit: $1 \mathrm{~mm}$ and $\mathrm{E}=$ height of the pitch: $1 \mathrm{~mm}$ ) was cleaned by ultrasound in acetone. This procedure was followed by rinsing with deionised water and electric polishing. The electrolyte used in this process was a mixture of $\mathrm{C}_{2} \mathrm{H}_{5} \mathrm{OH}$ and $\mathrm{HClO}_{4}$ (volume ratio $=10: 1$ ), while the operating voltage was kept constant at 15 volts. During electric polishing, the solution was stirred using a mechanical stirring $(800 \mathrm{rpm})$ and kept at a constant temperature of $25{ }^{\circ} \mathrm{C}$. After electric polishing, all samples were rinsed with deionised water and dried in the air. The electrochemical cell consists of a two electrode: platinum plate act as the anode electrode and zirconium as a cathode electrode. All anodising experiments were performed at applied voltage 30 volts, 4 hours with mechanical stirring (300 rpm) at a room temperature; the electrolyte solution consists of $0.2 \mathrm{M} \mathrm{HF}$ and $0.6 \mathrm{M}$ $\mathrm{Na}_{2} \mathrm{SO}_{4}$ with the addition of variable glycerine in the range from 0 to $60 \%$.

\section{Animal model}

New Zealand rabbits white were used in this work: The colour of the fur is white, average male weight of $4-5 \mathrm{~kg}$ and is characterised by rapid growth (official ethics review approval number of animal experiments and license number of experimental animals (2345/ $\mathrm{m} / 10-01-2020)$ ).

Animals are purchased from the Ministry of Health, National Centre for Drug Control and Research (NCDCR). The collected rabbits were housed in special cages for 7 days before the operation as shown in Fig. 2. All animals received antiparasitic drug (Ivermectine 0.1 $\mathrm{mg} / \mathrm{kg}$ ) before the operation to prevent the internal and external parasite. All instruments, towels and appliances were autoclaved at $121{ }^{\circ} \mathrm{C}$ and 20 bars for 30 minutes before operation. The surgical filed (thigh region) was prepared from the hip joint down towards the stifle joint for high aseptic surgical operation by clipping, shaving, washing with soap and tap water then disinfecting the area with $70 \%$ prepared alcohol (Fig. 3). All equipment which is essential for the operation was introduced that include the surgical instruments set, drapes and surgical gloves. The rabbits were off

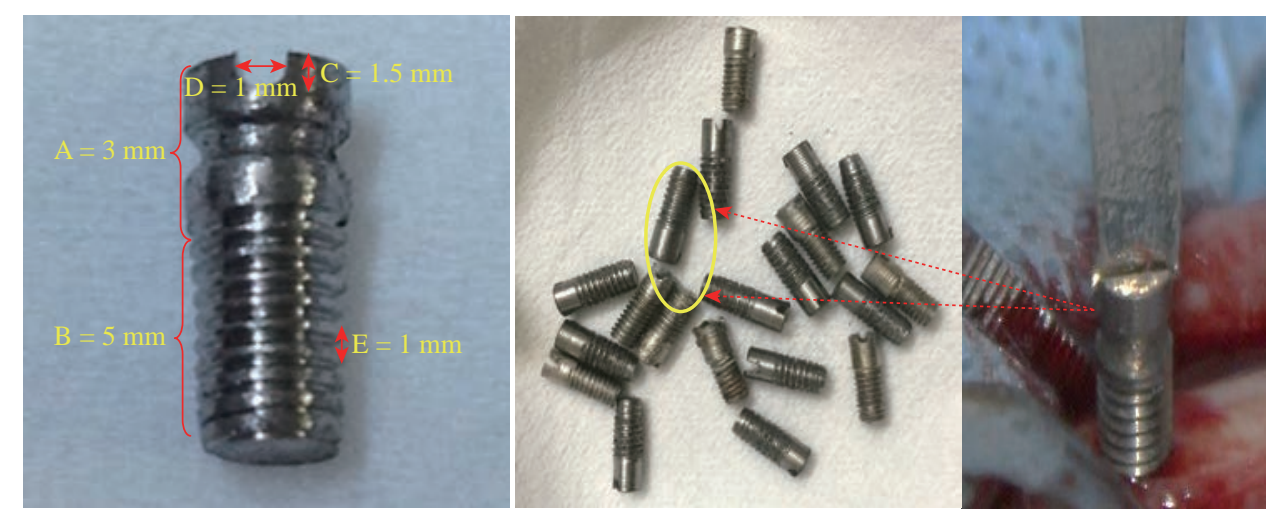

Fig. 1 Zirconium surgical screw used in this work. $A=$ smooth part length; $B=$ threaded part length; $C=$ length of slit; $D=$ diameter of slit, and $\mathrm{E}=$ height of the pitch. 


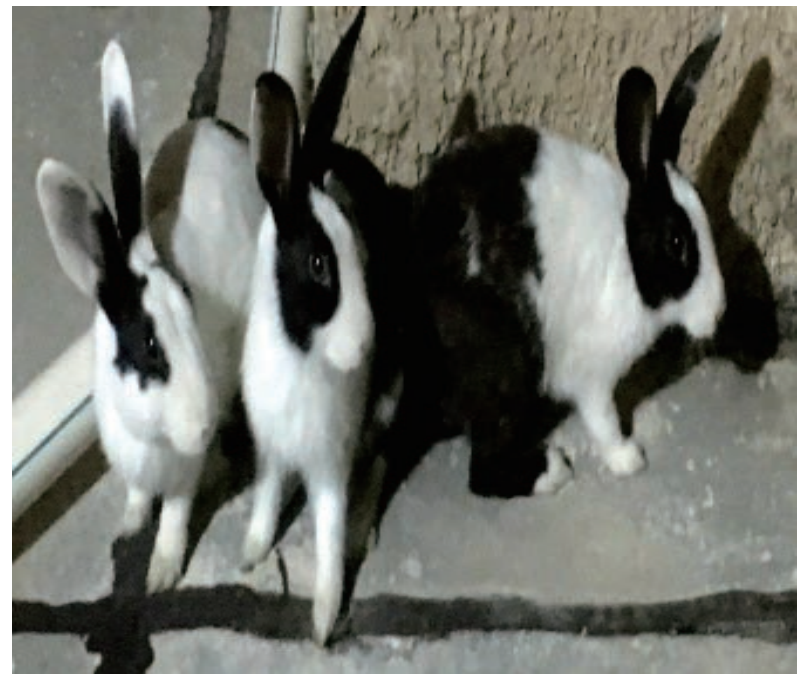

Fig. 2 The collected rabbits were housed in special cages.

food 12 hours and water 2 hours prior for operation. General anesthesia was done by intramuscular injection of $2 \%$ xylazine hydrochloride with a dose of $(17.5 \mathrm{mg} /$ $\mathrm{kg}), 5 \%$ Ketamine hydrochloride $(25 \mathrm{mg} / \mathrm{kg})$ and $0.5 \mathrm{cc}$ lidocaine injected along the site of incision. The dose of antibiotic and anesthesia was calculated according to the following formula:

\section{Dose $=$}

animals weight $\times$ dose rate $\div$ concentration of drug.

Following up the induction of anesthesia, the animals laid down at the lateral recumbence, the whole body was covered with sterile drapes except the surgical field by, which was coated with cotton imbedded with alcohol then scratched with $2 \%$ iodine tincture. Approximately $4 \mathrm{~cm}$ surgical incision length was done at lateral aspect of thigh region from the great trochanter to the lateral side of the patella, bleeding was arrested routinely the subcutaneous tissue dissected, fascia lata sharply was dissected then the underlying biceps femoral is and vastus laterals muscle were bluntly separated to expose the mid shift of the femoral bone. Then with curved and fine artery forceps dissected around the femoral bone at the site of fracture to separate the abducted muscle, protect the adjacent soft tissues using two curved scissor around the bone then using a mechanical puncture tool for making a hole in the centre of the femur and fixing the surgical screw. Penicillin powder was applied as local antibiotics, the muscles and fascia lata sutured by simple continuous pattern using 2/0 chromic cat gut each one alone, the skin closed via simple interrupted pattern using 2/0 non absorbable silk materials.
All the animals were observed daily for the normal physiological activities and animals behavior for post operation along the experimental duration.

\section{Results and Discussion SEM of zirconium and zirconium oxide surgical screw}

Fig. 4 shows SEM pictures of zirconium and zirconium oxide surgical screw used in this research under microscope, where pictures show the exact dimensions of the surgical screw in terms of diameter, length, and surface. The result showed that the surface is homogeneous, without cracks, in the zirconium section. As for the photos of zirconium oxide, the nanotubes appear to be formed in a way that helps improve the biological integration and mechanical properties of treating bone fractures. Zirconium oxide has strong toughness against breakage, as it is characterised by its high resistance to oxidation, which reduces chemical corrosion. The properties of this component have made it a new and alternative option for well-known dental crowns manufacturing materials in the dental field. Zirconium oxide can be easily modified, reconfigured and recoloured.

\section{EDXS of zirconium and zirconium oxide surgical screw}

EDXS profile confirmed the signal characteristic of zirconium and oxygen. EDXS profile is another evidence of pure $\mathrm{ZrO}_{2}$ nanotubes formation. Fig. 5 presents peaks between 0.525 and $2.044 \mathrm{kV}$, which indicate the presence of $\mathrm{ZrO}_{2}$ compounds. The zirconium content at the level of $80.6 \%$ and the oxygen content at the level of $19.3 \%$ as given in Fig. 5(b). The figure also shows that there are no other elements included in the composition of the orthopaedic implant, which means that the implant is of high purity as it has a significant effect in increasing the speed of bone fusion between the surface modified nanostructure and bone [29, 30]. The attached Table 1 below the picture shows the proportions of the elements according to the periodic table, where each element is classified according to the atomic number and energy levels as mentioned in the table, in general the table is another confirmation of the purity of the bone implant within acceptable weight ratios.

\section{SEM of zirconium oxide nano tube prepared via chemical method}

Fig. 6 shows the structural properties carried out 


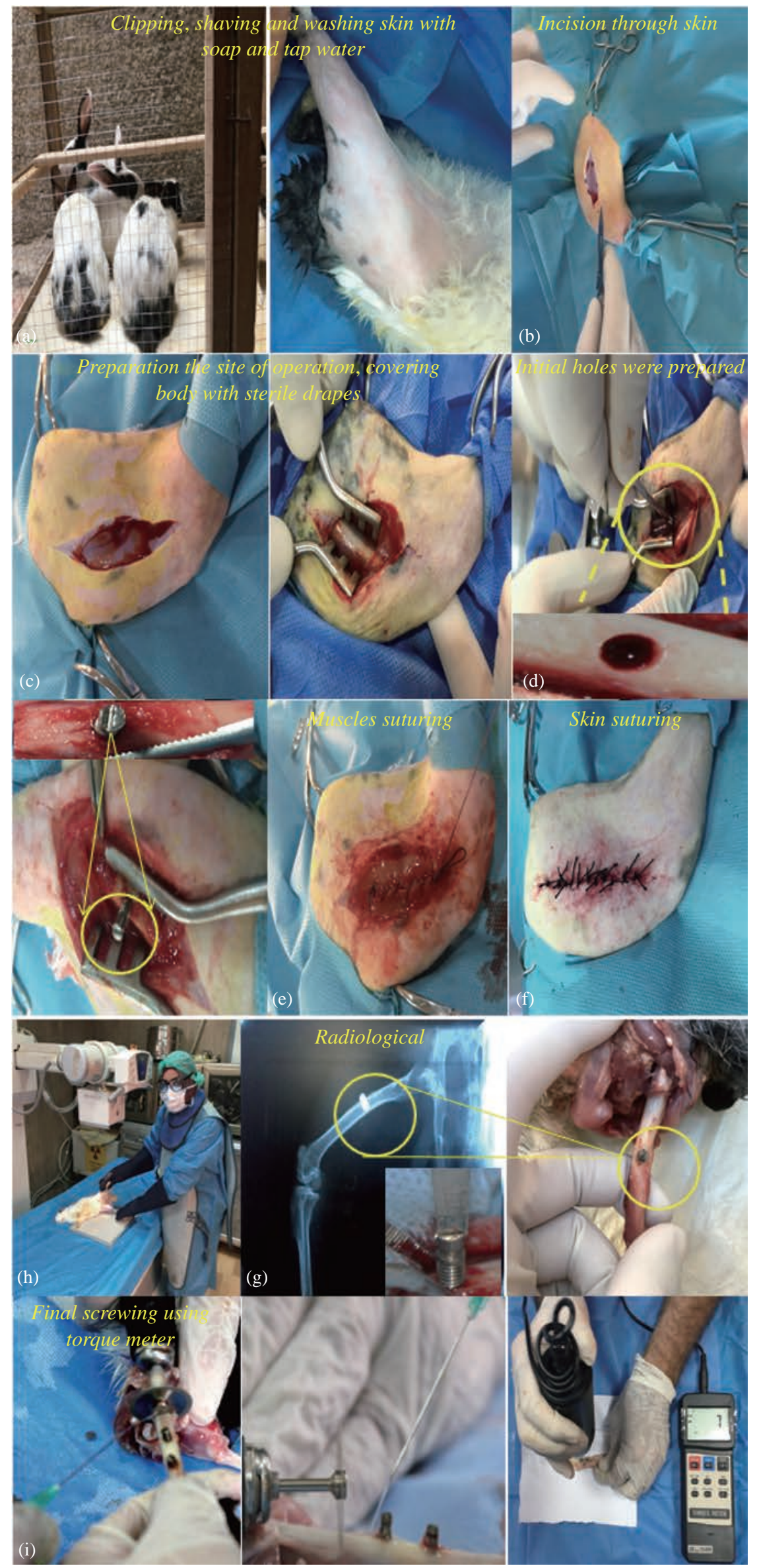

Fig. 3 The surgical steps used in this research. 

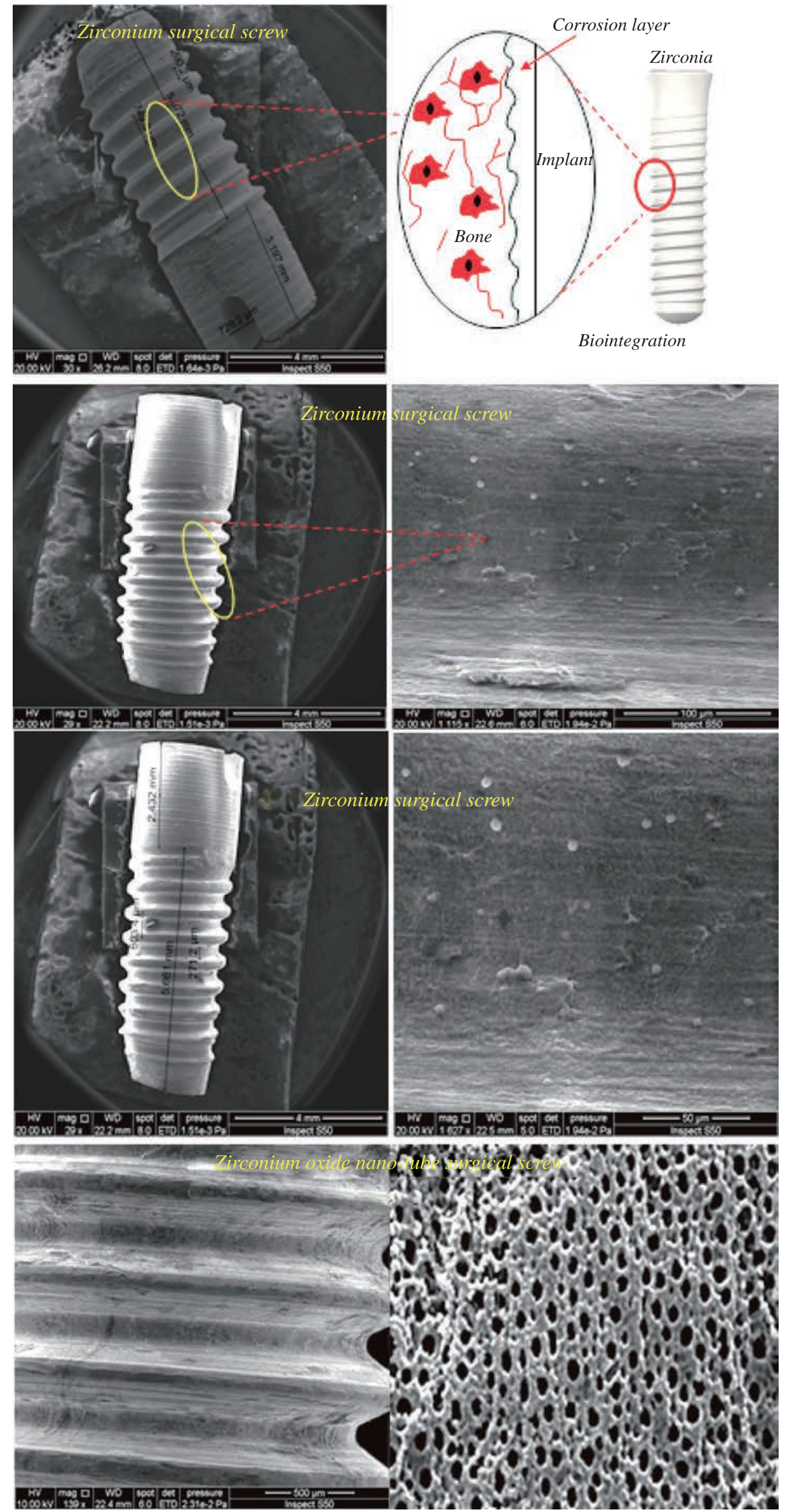

Fig. 4 Grown zirconium oxide nanotube bundles on zirconium surgical screw. 


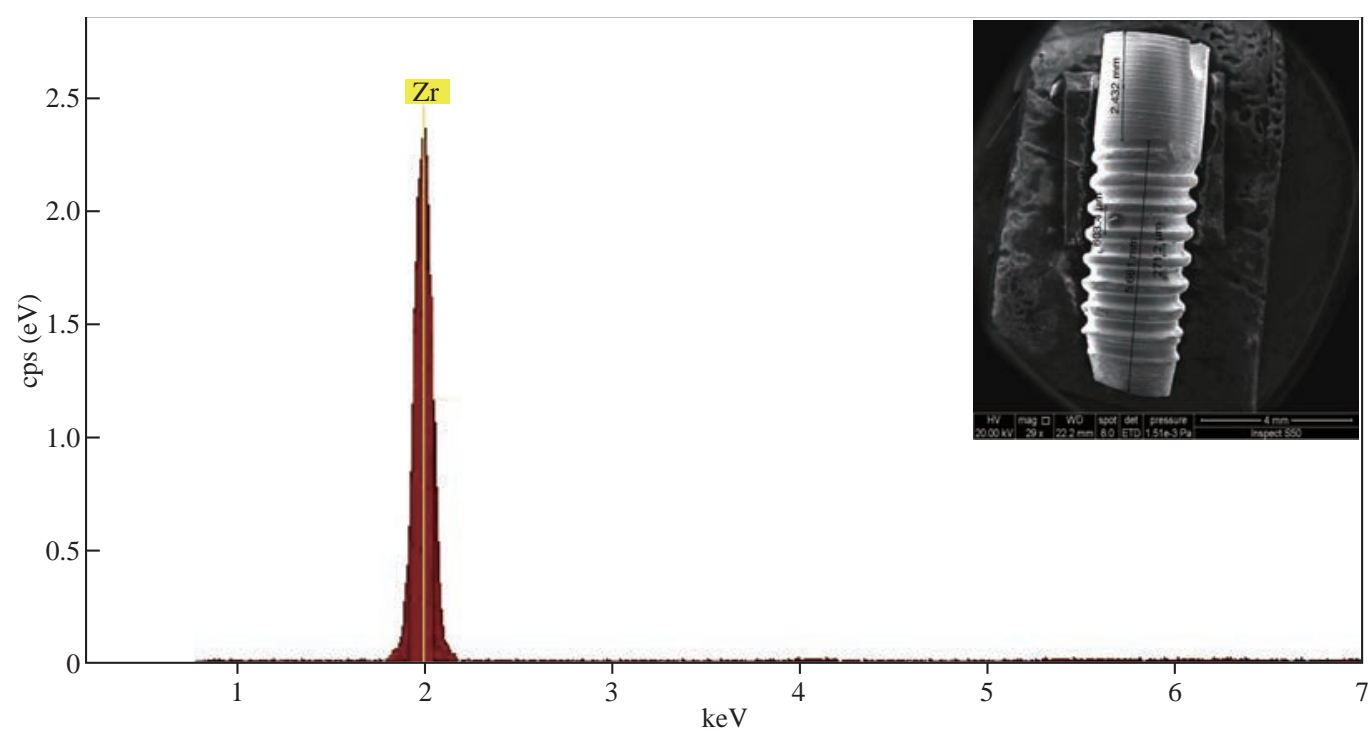

(a) Zr surgical screws

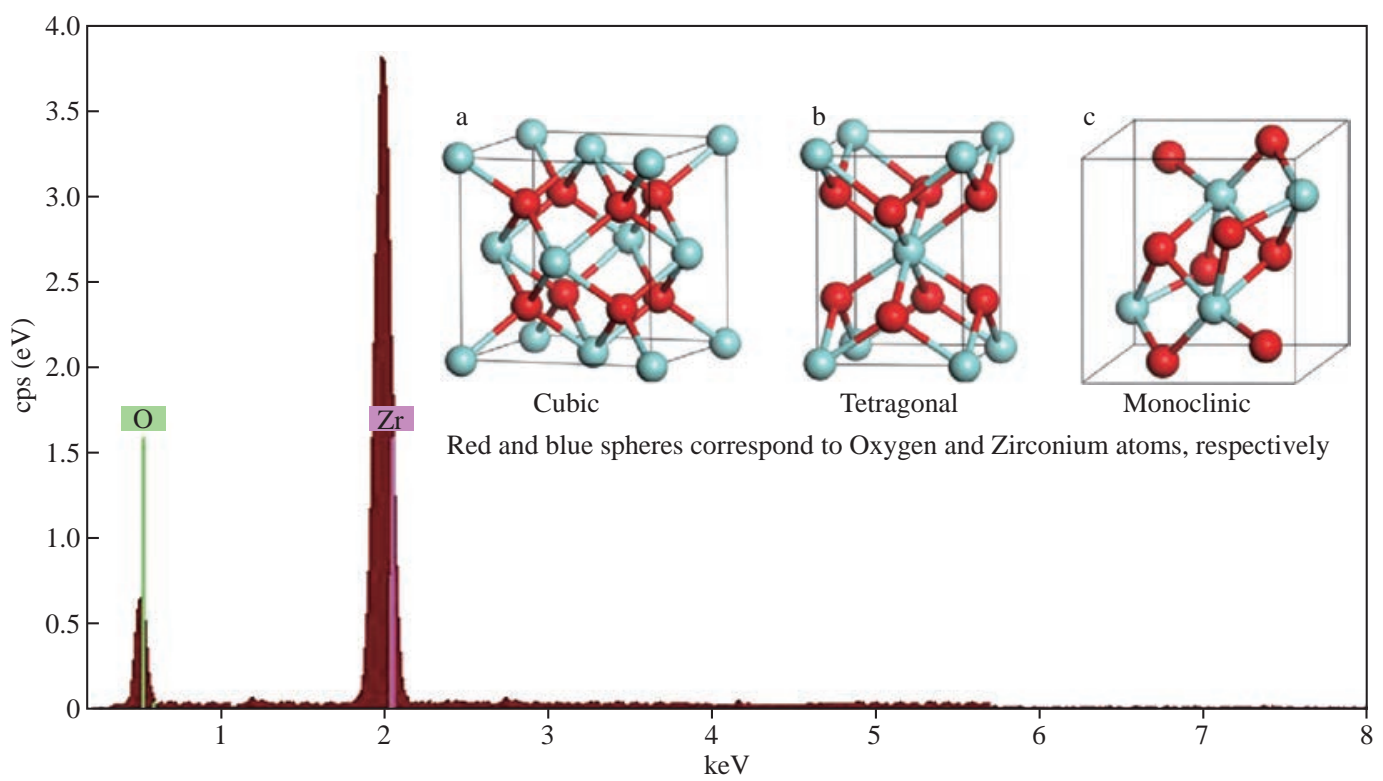

(b) $\mathrm{ZrO}_{2}$ surgical screws

Fig. 5 Energy dispersive $\mathrm{X}$-ray spectrometry of $\mathrm{ZrO}_{2}$ nanotubes on as machine $\mathrm{Zr}$ screws (before implantation). (a) $\mathrm{Zr}$ surgical screw and (b) $\mathrm{ZrO}_{2}$ nano-tube surgical screw.

Table 1 Energy dispersive X-ray spectrometry of $\mathrm{ZrO}_{2}$ nanotubes on as machine $\mathrm{Zr}$ screws (before implantation)

\begin{tabular}{|c|c|c|c|c|c|c|}
\hline \multicolumn{7}{|c|}{ Zr surgical screw } \\
\hline Element & $\mathrm{AN}$ & series & [wt.\%] & [norm. wt.\%] & [Norm. at. \%] & Error in wt.\% (1 Sigma) \\
\hline \multirow[t]{2}{*}{ Zirconium } & 40 & L-series & 65.6482 & 100 & 100 & 4.755285 \\
\hline & & Sum: & 65.6482 & 100 & 100 & \\
\hline \multicolumn{7}{|c|}{$\mathrm{ZrO}_{2}$ nano-tube surgical screw } \\
\hline Element & $\mathrm{AN}$ & series & [wt.\%] & [norm. wt.\%] & [Norm. at. \%] & Error in wt.\% (1 Sigma) \\
\hline Zirconium & 40 & L-series & 85.63499 & 80.63499 & 79.83057 & 4.322638 \\
\hline \multirow[t]{2}{*}{ Oxygen } & 8 & K-series & 30.36501 & 19.36501 & 20.16943 & 0.452748 \\
\hline & & Sum: & 116 & 100 & 100 & \\
\hline
\end{tabular}

by scanning electron microscope (SEM) of zirconium oxide nano tube prepared via chemical method in the electrolyte solution consists of $0.2 \mathrm{M} \mathrm{HF}$ and 0.6 $\mathrm{M} \mathrm{Na}_{2} \mathrm{SO}_{4}$ and the effect of glycerine concentration variable in the range from 0 to $60 \%$ addition on the diameter and length of the prepared nanotube was studied in this work. The result showed that homogeneous nanotubes are larger in diameter with increasing concentration of glycerine. When preparing zirconium oxide nanotubes without adding glycerol, 


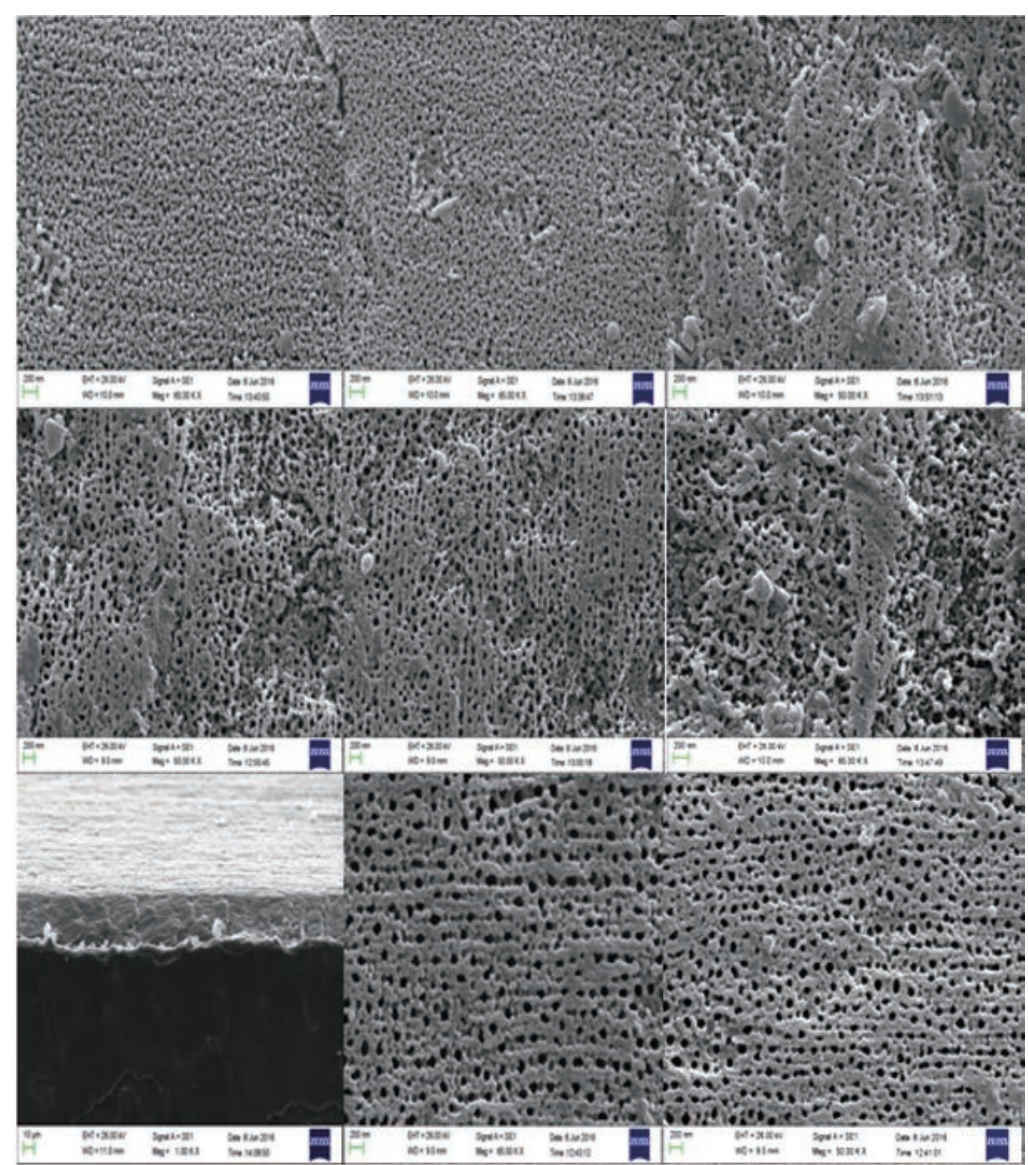

(a) $0.2 \mathrm{M} \mathrm{HF}$ and $0.6 \mathrm{M} \mathrm{Na}_{2} \mathrm{SO}_{4}$

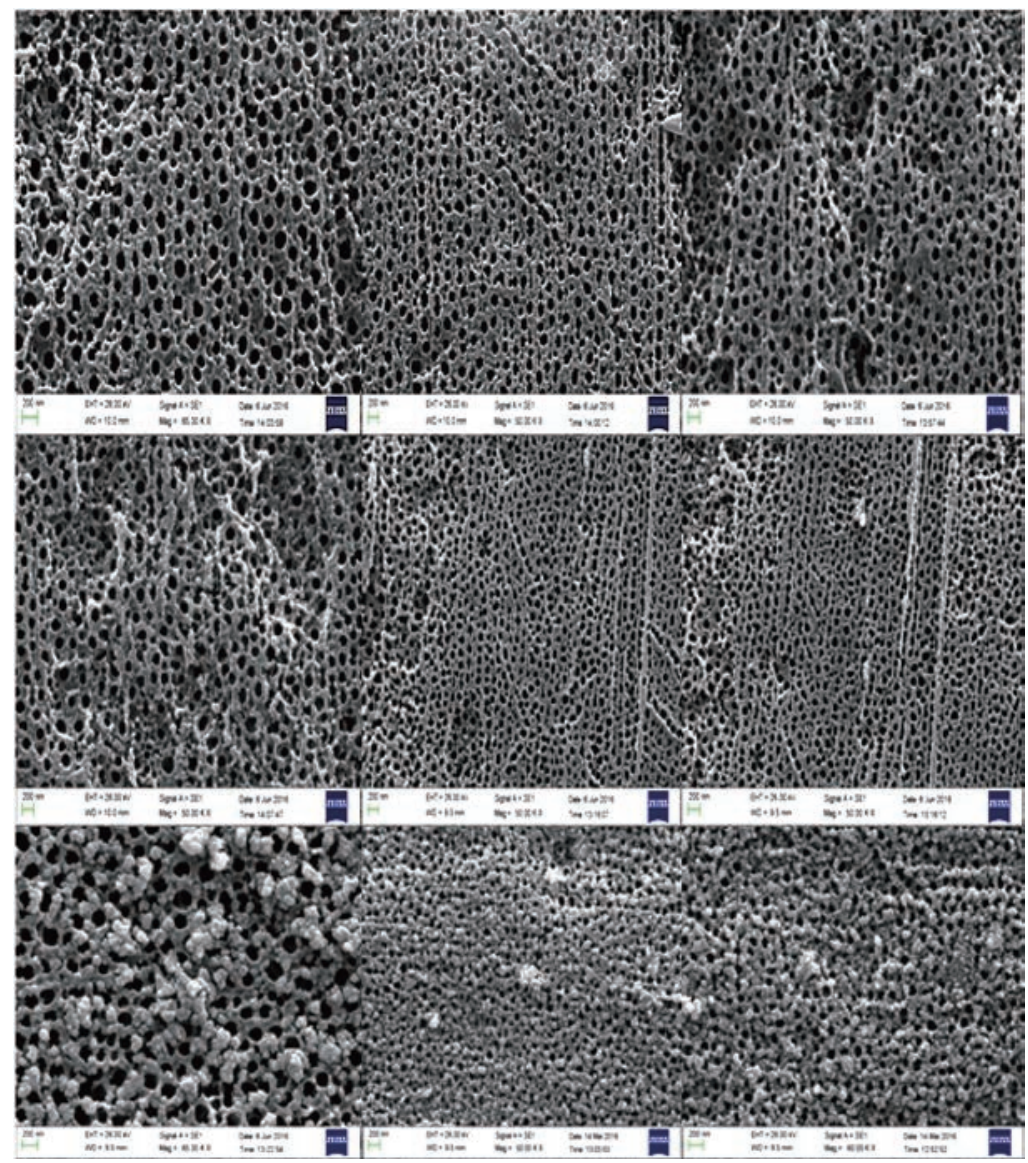

(b) $0.2 \mathrm{M} \mathrm{HF}$ and $0.6 \mathrm{M} \mathrm{Na}_{2} \mathrm{SO}_{4}$ with the addition of $20 \%$ glycerin 


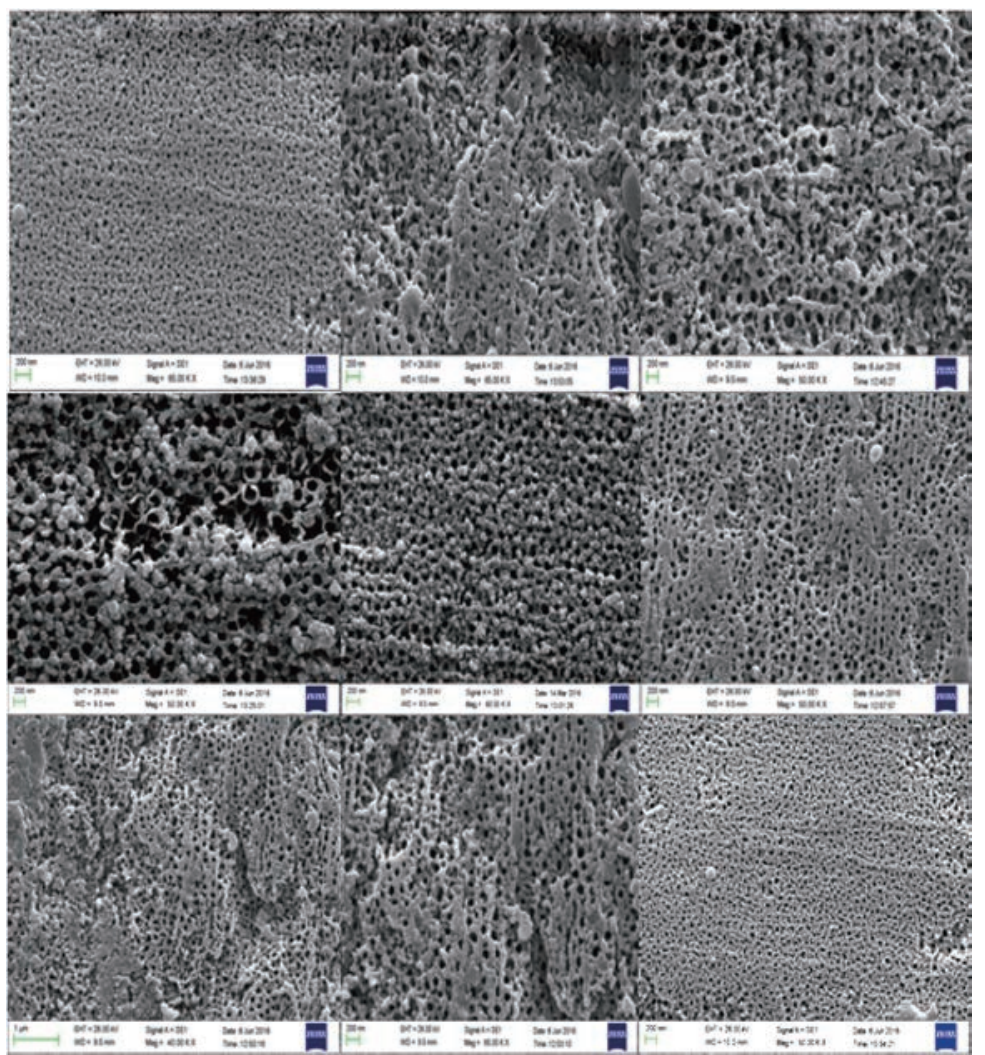

(c) $0.2 \mathrm{M} \mathrm{HF}$ and $0.6 \mathrm{M} \mathrm{Na}_{2} \mathrm{SO}_{4}$ with the addition of $40 \%$ glycerin

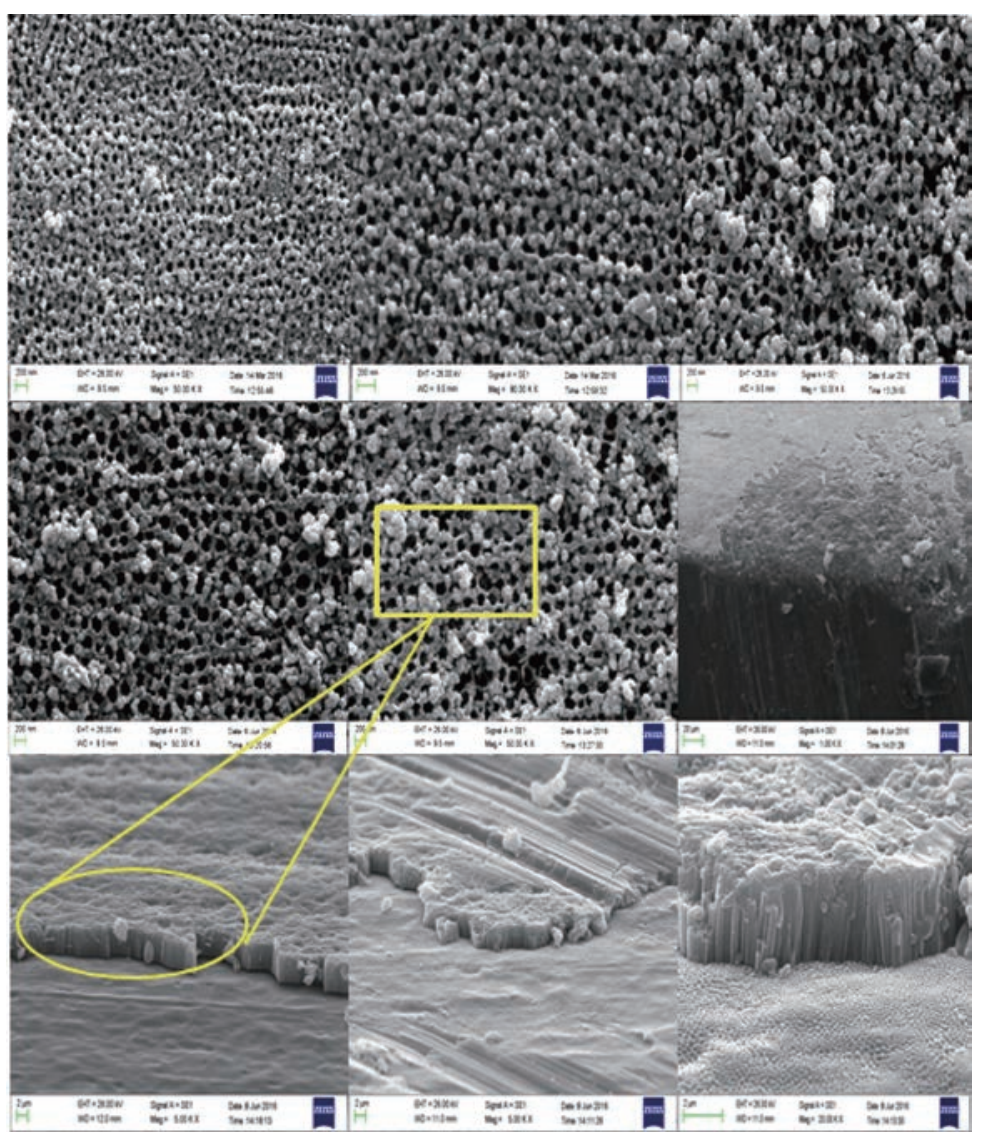

(d) $0.2 \mathrm{M} \mathrm{HF}$ and $0.6 \mathrm{M} \mathrm{Na}_{2} \mathrm{SO}_{4}$ with the addition of $60 \%$ glycerin

Fig. $6 \mathrm{SEM}$ of $\mathrm{ZrO}_{2}$ nano-tubes on as machine $\mathrm{Zr}$ screws (before implantation). (a) Electrolyte solution consisting of $0.2 \mathrm{M} \mathrm{HF}$ and $0.6 \mathrm{M} \mathrm{Na}_{2} \mathrm{SO}_{4}$, (b) electrolyte solution consisting of $0.2 \mathrm{M} \mathrm{HF}$ and $0.6 \mathrm{M} \mathrm{Na}_{2} \mathrm{SO}_{4}$ with the addition of $20 \%$ glycerine, (c) electrolyte solution consisting of $0.2 \mathrm{M} \mathrm{HF}$ and $0.6 \mathrm{M} \mathrm{Na}_{2} \mathrm{SO}_{4}$ with the addition of $40 \%$ glycerine, and (d) electrolyte solution consisting of 0.2 $\mathrm{M} \mathrm{HF}$ and $0.6 \mathrm{M} \mathrm{Na}_{2} \mathrm{SO}_{4}$ with the addition of $60 \%$ glycerine. 
the surface is coarser, with a diameter of less than $70 \mathrm{~nm}$ and the formation of nanoparticles around the tube opening may be due to the incomplete growth of the zirconium oxide nanotubes as shown in the cross section of the sample as shown in Fig. 6(a).

Fig. 6(b) showing zirconium oxide nanotubes prepared after adding $20 \%, 40 \%$ and $60 \%$ glycerine to the electrolyte, where the images show that the diameters of the nanotubes are larger, smoother and higher porosity, which helps to increase the effectiveness of bone fusion and increase the growth of new bone and this is the main reason for improving the surface of the zirconium implant. The increased porosity of the bone implant makes it provide sufficient mechanical support to facilitate bone regeneration. Meanwhile, mechanical properties, such as stiffness, must be compatible with the surrounding bone tissue to obtain longevity by avoiding so-called stress prevention [14]. Thus, the surface of the orthopaedic implant becomes porous by adjusting the size of pores and their distribution.

Increasing the percentage of glycerine added to the electrolyte to a level of $60 \%$. The growth of zirconium oxide nanotubes is completed to become more homogeneous as shown in Fig. 6(c) and (d). The pictures also show the presence of some broken tubes on the side as shown in Fig. 6(c), which makes us choose the best percentage of addition to glycerine which is $40 \%$. The hypothesis of bone growth is that cells adhere to the surface of materials and move to the internal space (porosity found to be $120 \mu \mathrm{m}$ ), which has an important relationship to the properties of the structure as shown in SEM pictures. When manufacturing an implant to repair bone defects, both cellular compatibility and mechanical properties must be considered [7].
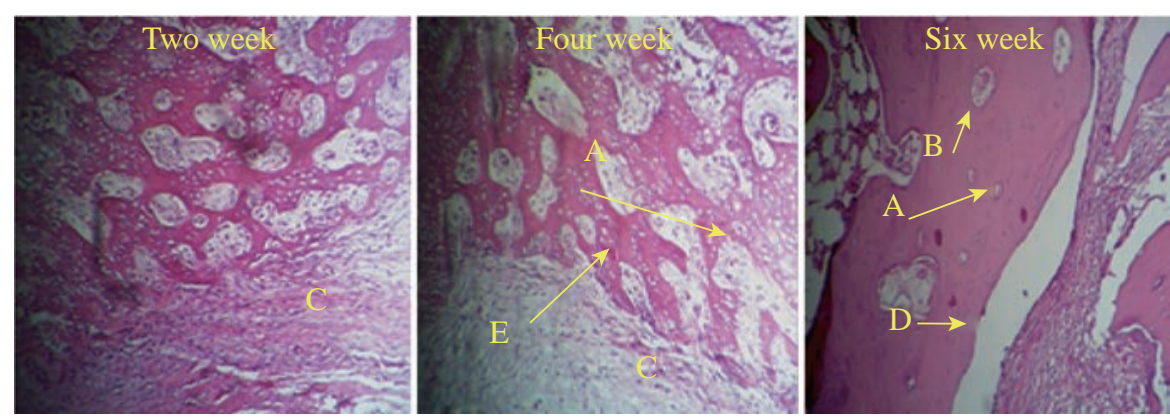

(a) $0.2 \mathrm{M} \mathrm{HF}$ and $0.6 \mathrm{M} \mathrm{Na}_{2} \mathrm{SO}_{4}$ with the addition of $20 \%$ glycerin
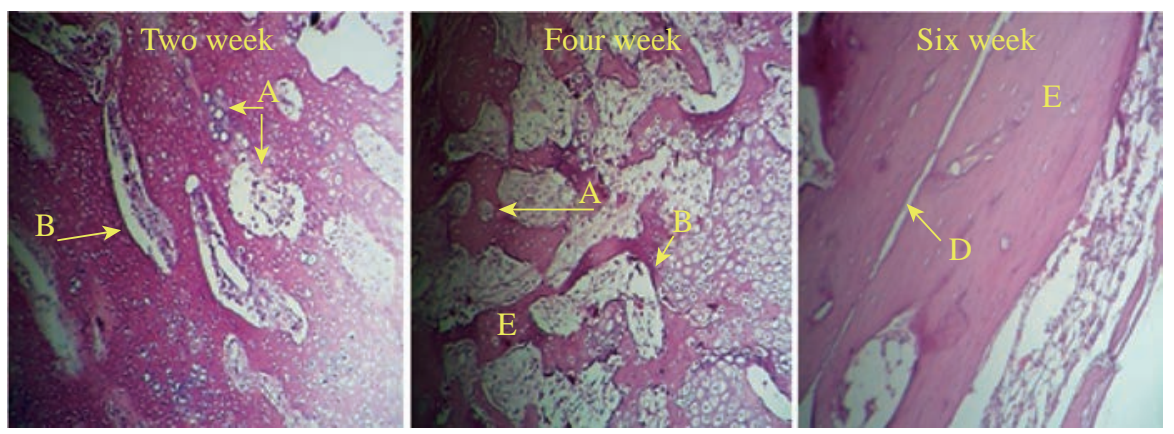

(b) $0.2 \mathrm{M} \mathrm{HF}$ and $0.6 \mathrm{M} \mathrm{Na}_{2} \mathrm{SO}_{4}$ with the addition of $40 \%$ glycerin
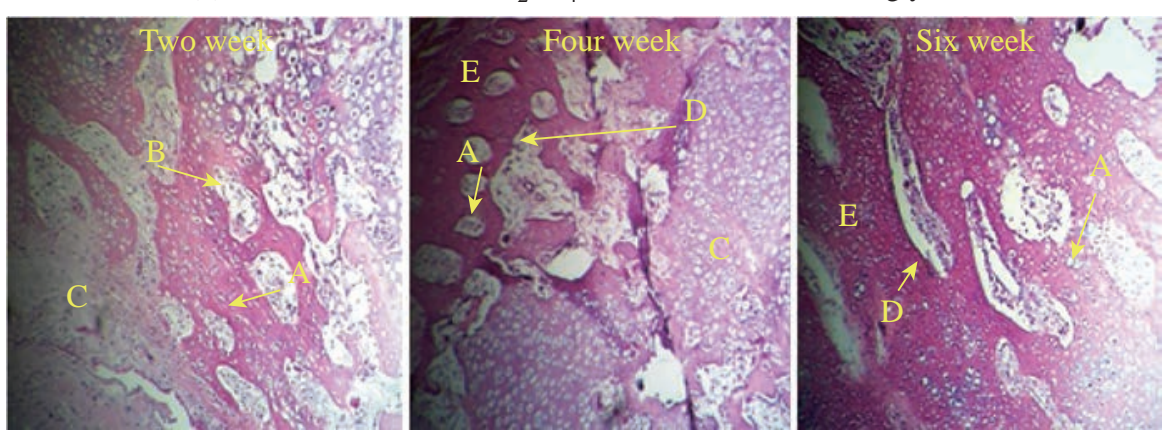

(c) $0.2 \mathrm{M} \mathrm{HF}$ and $0.6 \mathrm{M} \mathrm{Na}_{2} \mathrm{SO}_{4}$ with the addition of $60 \%$ glycerin

Fig. 7 Histological analysis for all groups. $\mathrm{H} \& \mathrm{E} \times 4, \times 10$ and $\times 40 . \mathrm{A}=$ Osteoblasts, $\mathrm{B}=$ Osteocytes, $\mathrm{C}=$ Osteoid, $\mathrm{D}=\mathrm{Cement}$ line, and $\mathrm{E}=$ Bone. 
Histological and radiological analysis of zirconium and zirconium oxide surgical screw

All animals recovered well from the anaesthesia and the surgical procedure. No implant dislocation and incision infection occurred during the experiment. Histopathological and Radiological examinations showed the filling of the bone lakes at the implant site with live bone cells and the penetration of Haversian canals into the blood vessels as shown in Fig. 7 and 8. The images showed an increase in bone density and hardness in all groups in the new bone formation area between the implant's connections with the host bone. The activity of osteoblasts, due to activity in the secretion and release of the basic enzyme phosphatase, which leads to an increase in calcium precipitation and an increase in the strength of the new bone formed and thus the stability and survival of the implant [29, 30]. The formation of collagen and vascular fibres has an impact on improving the attachment of the implant and host bone, penetration of the bone cells and blood vessels into the implant surface, and increased bone fusion. In this results observed implant area (ends and middle) were filled with new bone, remodelled into mature lamellar bone and the same properties are found in internal porous areas. The continuity of bone was recovered from proximal to distal through follicular implantation. The mechanically adapted follicular implantation acquired good bone growth according to histological assessments. The tissue grown in the implant was evenly distributed, which was attributed to the good bonding of the implant, which indicates the advantage of the additive manufacturing method compared to the conventional methods. Place the bone directly on the implant surface at 3 months after the surgery, and bone callus is also observed surrounding the implant. The depth of bone growth gradually becomes deeper and the area $(0.5 \mathrm{~cm})$ of bone in the implant becomes larger over time. At each time point, the bone area at both ends was higher than that in the middle position. This is consistent with the direction of bone growth and remodelling. The result of histopathology analysis indicated that the proximal regions significantly higher compared to the distal regions in terms of bone area could be explained mainly by the difference in blood supply. The segmental periosteum was destroyed when bone defects occurred, and blood flow in the distal region was somewhat decreased postoperatively [14, 29, 30].

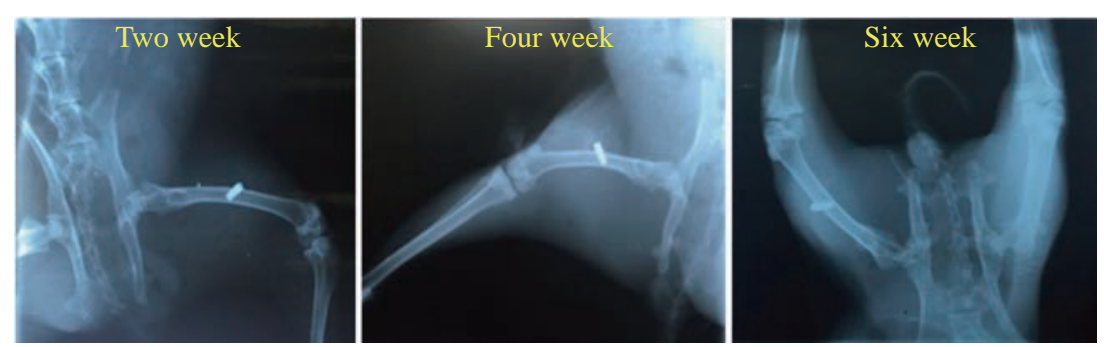

(a) $0.2 \mathrm{M} \mathrm{HF}$ and $0.6 \mathrm{M} \mathrm{Na}_{2} \mathrm{SO}_{4}$ with the addition of $20 \%$ glycerin

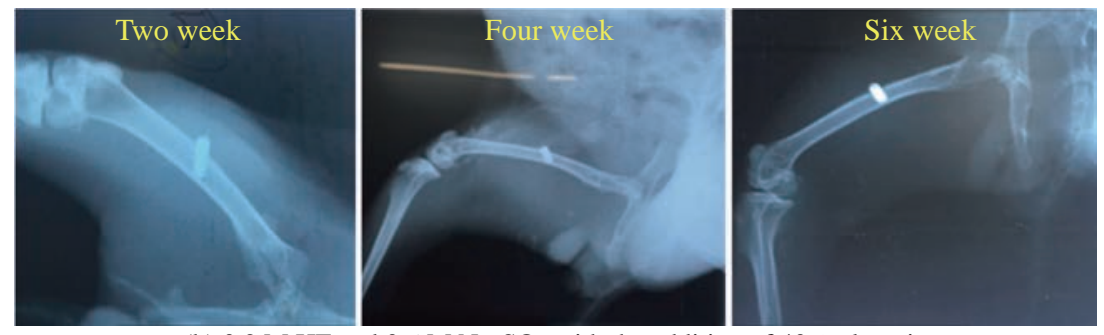

(b) $0.2 \mathrm{M} \mathrm{HF}$ and $0.6 \mathrm{M} \mathrm{Na}_{2} \mathrm{SO}_{4}$ with the addition of $40 \%$ glycerin
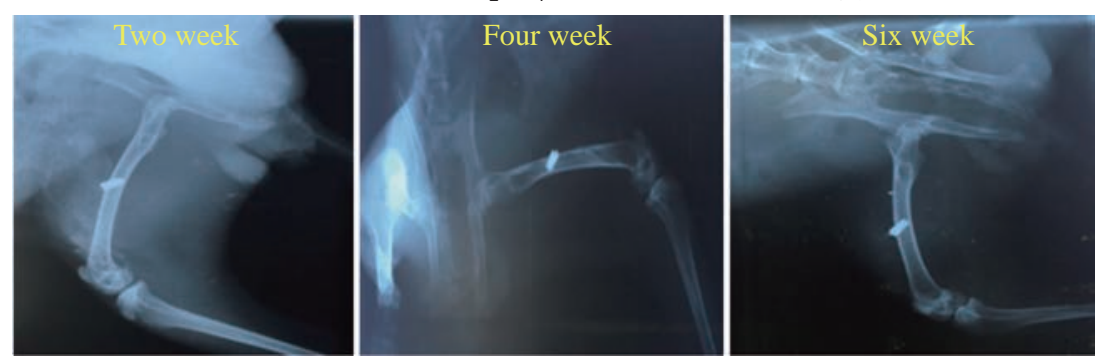

(c) $0.2 \mathrm{M} \mathrm{HF}$ and $0.6 \mathrm{M} \mathrm{Na}_{2} \mathrm{SO}_{4}$ with the addition of $60 \%$ glycerin

Fig. 8 Radiological analysis for all groups. (a) $0.2 \mathrm{M} \mathrm{HF}$ and $0.6 \mathrm{M} \mathrm{Na}_{2} \mathrm{SO}_{4}$ with the addition of $20 \%$ glycerin, (b) $0.2 \mathrm{M} \mathrm{HF}$ and 0.6 $\mathrm{M} \mathrm{Na}_{2} \mathrm{SO}_{4}$ with the addition of $40 \%$ glycerin, and (c) $0.2 \mathrm{M} \mathrm{HF}$ and $0.6 \mathrm{M} \mathrm{Na}_{2} \mathrm{SO}_{4}$ with the addition of $60 \%$ glycerin. 


\section{Conclusions}

In this research, zirconium oxide nanotubes were prepared using a simple chemical method, and a study of the effect of glycerine addition on the diameter of nanotubes formed. When preparing zirconium oxide nanotubes without adding glycerol, the surface is coarser, with a diameter of less than $70 \mathrm{~nm}$ and the formation of nanoparticles around the tube opening may be due to the incomplete growth of the zirconium oxide nanotubes. SEM showing zirconium oxide nanotubes prepared after adding 20\%, 40\% and 60\% glycerine to the electrolyte, where the images show that the diameters of the nanotubes are larger, smoother and higher porosity, which helps to increase the effectiveness of bone fusion and increase the growth of new bone and this is the main reason for improving the surface of the zirconium implant. The increased porosity (120-200 $\mu \mathrm{m})$ of the bone implant makes it provide sufficient mechanical support to facilitate bone regeneration. Meanwhile, mechanical properties, such as stiffness, must be compatible with the surrounding bone tissue to obtain longevity by avoiding so-called stress prevention. Thus, the surface of the orthopaedic implant becomes porous by adjusting the size of pores and their distribution. Histopathological examinations showed the filling of the bone lakes at the implant site with live bone cells and the penetration of Haversian canals into the blood vessels. Histopathological images showed an increase in bone density and hardness in all groups in the new bone formation area between the implant>s connections with the host bone. The activity of osteoblasts, due to activity in the secretion and release of the basic enzyme phosphatase, which leads to an increase in calcium precipitation and an increase in the strength of the new bone formed and thus the stability and survival of the implant.

\section{Conflict of Interests}

The authors declare that no competing interest exists.

\section{References}

[1] C.L. Gregson, M.A. Paggiosi, N. Crabtree, et al., Analysis of body composition in individuals with high bone mass reveals a marked increase in fat mass in women but not men. J. Clin. Endocrinol. Metab. 2013, 98: 818-828.

[2] D. Farlay, G. Boivin, mineral quality. Osteoporosis. In Tech, 2012: 3-32.
[3] E. Donnelly, D.S. Meredith, J.T. Nguyen, et al., Bone tissue composition varies across anatomic sites in the proximal femur and the iliac crest. J. Orthop. Res., 2012, 30: 700-706.

[4] E.T. Everett, Fluoride's effects on the formation of teeth and bones and the influence of genetics. J. Dent. Res., 2011, 90: 552-560.

[5] J.R. Caeiro, P. González, and D. Guede, Biomechanics and bone (\& II): Trials in different hierarchical levels of bone and alternative tools for the determination of bone strength. Rev. Osteoporos. y Metab. Miner., 2013, 5: 99108.

[6] M.J. Bojrab, D.R. Waldron, and J.P. Toombs, Current techniques in small animal surgery, $5^{\text {th }}$ edition. CRC Press, Taylor and Francis Group, 2014: 1183.

[7] D. Fang, J. Yu, Z. Luo, et al., Fabrication parameterdependent morphologies of self-organized $\mathrm{ZrO}_{2}$ nanotubes during anodization. J Solid State Electrochem. 2012, 16: 1219-1228.

[8] D. Fang, Z. Luo, S. Liu, et al., Photoluminescence properties and photocatalytic activities of zirconia nanotube arrays fabricated by anodization”, Opt Mater 2013; 35: 1461-1466.

[9] C.R. Babu, N.R.M. Reddy, and K. Reddy, Synthesis and characterization of high dielectric nano zirconium oxide. Ceramics International, 2015, 41: 10675-10679.

[10] S.R. Mokhtaruddin, A.B. Mohamad, K.S. Loh, et al., Thermal properties and conductivity of Nafion-zirconia composite membrane. Malaysian Journal of Analytical Sciences, 2016, 20: 670-677.

[11] R. Sigwadi, S. Dhlamini, T. Mokrani, et al., Effect of synthesis temperature on particles size and morphology of zirconium oxide nanoparticle. Journal of Nano Research, 2017, 50: 18-31.

[12] Y. Lin, L. Zheng, L. Fan, et al., The epigenetic regulation in tooth development and regeneration. Curr. Stem Cell Res. Ther., 2018, 13.

[13] C. Gautam, J. Joyner, A. Gautam, et al., Zirconia based dental ceramics: Structure, mechanical properties, biocompatibility and applications. Dalton T., 2016, 45: 1010-1039.

[14] K. Balagangadharan, C.S. Viji, B. Arumugam, et al., Chitosan/nanohydroxyapatite/nano-zirconium dioxide scaffolds with miR-590-5p for bone regeneration. Int. J. Biol. Macromol., 2018, 111: 953-958.

[15] M.M. Gad, A. Rahoma, A.M. Al-Thobity, et al., Influence of incorporation of $\mathrm{ZrO}_{2}$ nanoparticles on the repair strength of polymethyl methacrylate denture bases. Int. J. Nanomed., 2016, 11: 5633-5643.

[16] C.I. Ossai, N. Raghavan, Nanostructure and nanomaterial characterization, growth mechanisms, and applications. Nanotechnol. Rev., 2017, 7.

[17] M. H. M. Daud, Y. Hsu Zenn, J.Q. Zaman, et al., Evaluation of shear bond strength of a novel nanozirconia and veneering ceramics. Ceram. Int., 2017, 43: 1272-1277.

[18] P. Song, C. Hu, X. Pei, et al., Dual modulation of crystallinity and macro-/microstructures of 3D printed porous titanium implants to enhance stability and osseointegration. J. Mater. Chem. B, 2019, 7: 2865-2877.

[19] Z. Huang, Z. Wang, C. Li, et al., Application of plasma sprayed zirconia coating in dental implant: Study in implant. J. Oral Implantol., 2018, 44: 17-124.

[20] N. Goonoo, A. Bhaw-Luximon, N. Goonoo, et al., Analyzing polymeric nano fibrous scaffold performances in diabetic animal models for translational chronic wound healing research. Nanotechnol. Rev., 2017, 6.

[21] B. Gaihre, A.C. Jayasuriya, Comparative investigation of porous nano-hydroxyapaptite/chitosan, nano-zirconia/ 
chitosan and novel nano-calcium zirconate/chitosan composite scaffolds for their potential applications in bone regeneration. Mater. Sci. Eng. C-Mater., 2018, 91: 330-339.

[22] E.S. A.V. Costa, J.A. Teixeira, C.C.B.O. Mota, et al., In vitro morphological, optical and microbiological evaluation of nanosilver fluoride in the remineralization of deciduous teeth enamel. Nanotechnol Rev., 2018, 7: 509-520.

[23] M. Gad, A.S. Arrejaie, M.S. Abdel-Halim, et al., The reinforcement effect of nano-zirconia on the transverse strength of repaired acrylic denture base. Int. J. Dent., 2016: 7094056.

[24] M.D. Jerez-Masaquiza, L. Fernández, G. González, et al., Electrochemical sensor based on prussian blue electrochemically deposited at $\mathrm{ZrO}_{2}$ doped carbon nanotubes glassy carbon modified electrode. Nanomaterials, 2020, 10(7): 1328.

[25] A. Meng, L. Lin, X. Yuan, et al., Ag/ $\mathrm{ZrO}_{2} /$ MWCNT nanocomposite as non-platinum electrocatalysts for enhanced oxygen reduction reaction. ChemCatChem, 2019, 11(12): 2900-2908.

[26] R.B. Anjaneyulu, B.S. Mohan, G.P. Naidu, et al., $\mathrm{ZrO}_{2} /$ $\mathrm{Fe}_{2} \mathrm{O}_{3} / \mathrm{RGO}$ nanocomposite: Good photocatalyst for dyes degradation. Physica E: Low-dimensional Systems and Nanostructures, 2019, 108: 105-111.

[27] I. Zhao, L. Li, J. Li, et al., Electrical transport properties of self-organized $\mathrm{ZrO}_{2}$ nanotube. ECS Journal of Solid State Science and Technology, 2019, 8(4): 258: 261.

[28] S.S. Ghahfarokhi, R.S. Mamoory, and A.G. Kalashami, Inverse precipitation synthesis of $\mathrm{ZrO}_{2}$ nanopowder and in-situ coating on MWCNTs. Ceramics International, 2018, 44(12): 13556-13564.

[29] M.A.M. Hassan, D.K. Kafi, Porous scaffold implantation for bone fractures healing. 2020 IOP Conf. Ser.: Mater. Sci. Eng., 2020, 928: 072085.

[30] M.A.M. Hassan, A.M. Abbas, and M.J.M. Ali, Construction of scaffold from MgO nanoparticle: Bone fracture healing. 2020 IOP Conf. Ser.: Mater. Sci. Eng., 2020, 928: 072133.

Copyright $\odot$ Asmaa Hadi Mohammed, Marwa Abdul Muhsien Hassan. This is an open-access article distributed under the terms of the Creative Commons Attribution License, which permits unrestricted use, distribution, and reproduction in any medium, provided the original author and source are credited. 